\title{
Real-time transfontanellar ultrasound- guided biventricular catheter placement for revision surgery: technical note
}

\author{
Mehmet Seçer ${ }^{1 *}$, Zeynep Nigar Varlıbaş ${ }^{2}$, Osman Arıkan Nacar ${ }^{3}$, Kadir $_{\text {I̧ınar }}{ }^{4}$ and Murat Ulutaş${ }^{4}$
}

\begin{abstract}
Background: Proximal catheterization failure is believed to be the result of obstruction of the catheter by the choroid plexus. Optimal catheter placement can reduce proximal catheter failure. It has been reported that placement of ventricular catheters with stereotaxy, ultrasound, and endoscopic methods can help to reduce proximal catheterization failure.
\end{abstract}

Aim: In cases with an open fontanelle that require VP shunt revision, proximal catheter failure can be reduced with transfontanellar ultrasound guidance.

Case description: A ventricular catheter had been placed via right parietooccipital burr hole with free-hand method. Three months later, the left lateral ventricle, particularly the frontal horn of the left lateral ventricle, was observed to be asymmetrically larger, so revision surgery was planned. The revision surgery was performed under transfontanellar ultrasound guidance to advance the existing catheter to the frontal horn of the contralateral ventricle. In revision cases, particularly those with an open fontanelle, the proximal catheter can be placed in the desired region without any issues under intraoperative transfontanellar ultrasound guidance.

Conclusion: In cases with an open fontanelle that require external ventricular drainage, VP shunt placement, or revision, proximal catheter failure can be reduced with transfontanellar ultrasound guidance.

Keywords: Transfontanellar ultrasound, VP shunt, Revision

\section{Background}

Ventriculoperitoneal (VP) shunt placement is one the most commonly performed neurosurgical interventions. More than one entry point has been described for VP placement, but the most common are the frontal and parietooccipital regions. Despite technological advances in catheter material and valve design, shunt failure rates are still high [1]. Proximal catheter failure is believed to be the result of obstruction of the catheter by the choroid plexus [2]. Optimal placement of the catheter may reduce proximal catheter failures. Reduced catheter failure rates have been reported by placing the ventricular catheter with stereotaxy, ultrasound, and endoscopic methods [2, 3].

\footnotetext{
* Correspondence: memetsecer@yahoo.com

${ }^{1}$ Department of Neurosurgery, Atakent Hospital, Adnan Menderes Mh. Ufuk

Sok. No:7, 77200 Yalova, Turkey

Full list of author information is available at the end of the article
}

Aim of the study

In revision cases, particularly those with an open fontanelle, the proximal catheter can be placed in the desired region with the use of intraoperative transfontanellar ultrasound guidance; hence, we present our case as a technical note.

\section{Technical note of the case}

The case had meningocele at birth and was operated on in our clinic when 3 days old. At post-op 1 month, the case developed hydrocephalus (Fig. 1a); a VP shunt was placed by placing a proximal catheter via right parietooccipital route with free-hand method. Early post-operative computed tomography $(\mathrm{CT})$ showed that the shunt was inside the occipital horn of the right lateral ventricle but it fell short (Fig. 1b); however, it filled when pressing on the shunt pump, and because abdominal ultrasound showed free fluid in the abdomen, it was 


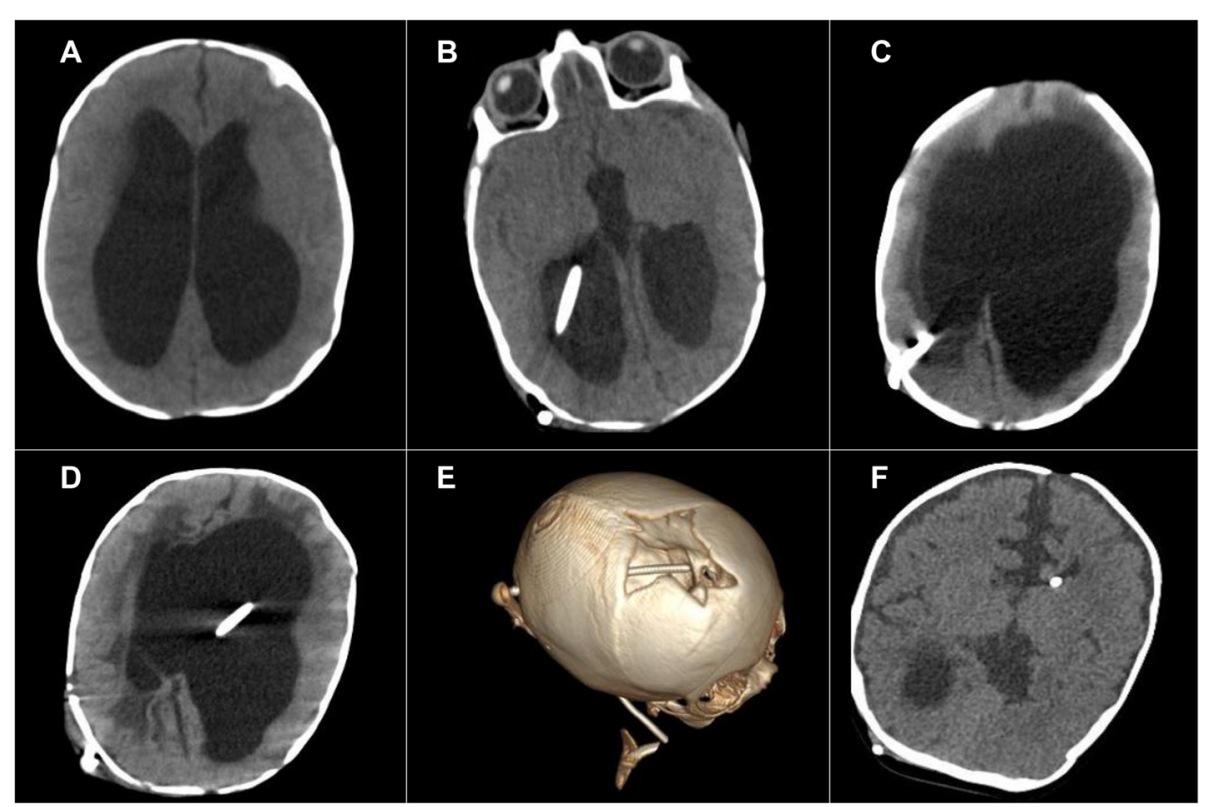

Fig. 1 a CT image showing hydrocephalus due to meningomyelocele. b Early image after VP shunt placement. c Asymmetrical ventricles at postop third month. $\mathbf{d} C T$ image showing early period after revision. e $C T$ image after reconstruction. $\mathbf{f} C T$ image showing late period

decided that the shunt was working. Three months later, the case was brought because the family noticed that there was bossing at the left front side of the head. Cranial CT showed asymmetrically enlarged left lateral ventricle, particularly the frontal horn (Fig. 1c), so a revision surgery was planned. During operation, it was seen that the proximal catheter tip was not occluded and was working properly. Proximal catheter was removed, and a new longer catheter was placed with the guide of a stylet. Under transfontanellar ultrasound (GE Voluson E8 11 L-D Linear probe) guidance, revision surgery was completed by advancing the proximal catheter to the enlarged left lateral ventricle (Figs. 1d, e and 2; Additional file 1). The catheter

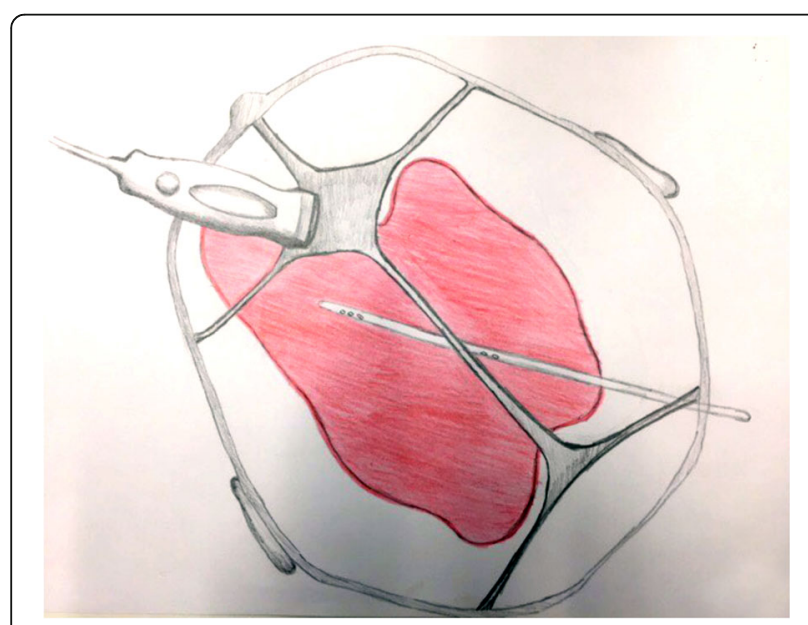

Fig. 2 Illustration of VP shunt revision under transfontanellar ultrasound guidance was placed approximately $7 \mathrm{~cm}$ in length against the ventricle. The new orientation of the proximal catheter did not affect the reservoir position, incision, and burr hole. At post-revision sixth month control, both ventricles were observed to be of normal size (Fig. 1f).

We describe a case of an infant with proximal shunt failure where shunt revision was performed under transfontanelle ultrasound guidance.

\section{Discussion}

VP shunt allows life-long cerebrospinal fluid (CSF) drainage; however, its malfunction is an important problem $[4,5]$. In pediatric cases, the rate of revision requirement is $16 \%$ within the first month and may be up to $39 \%$ within the first year [5]. Major causes of shunt malfunction include obstruction, infection, and malposition. It has been reported that free-hand method results in malposition of the shunt in $12.3-44 \%$ of cases $[3,5]$. Since our case had a unilaterally enlarged ventricle, partial malfunction due to shortness of the proximal catheter was suspected. While free-hand method is performed according to anatomical landmarks, several advanced techniques including stereotaxic navigation, ultrasonography, and endoscopy are recommended to improve the quality of catheter placement $[3,6]$. In the free-hand method, the presence of CSF drainage from the catheter tip does not necessarily mean that the shunt is in correct size and location within the ventricle. In pediatric patients, although endoscopic ventricular catheter placement reduces catheter failure rates, overall failure rates have been reported to be the same [2]. In a 
comparison of ultrasound with stereotaxic navigation, the speed of set-up, lack of requirement for additional imaging, and visualization in real-time are the important advantages to ultrasound [7]. In terms of proximal catheter position, ultrasound-guided VP shunt or external ventricular catheterization is known to be more successful compared to free-hand method [7-9]. However, while an additional burr hole or a larger burr hole is needed with a burr hole-type ultrasound probe for ultrasound guidance in adults [7], transfontanellar ultrasound is a more minimally invasive method in infants with an open fontanelle. Shkolnik and McLone placed a VP shunt with the help of transfontanelle ultrasound in seven hydrocephalic patients, one being a revision. In their practice, the proximal catheter tip is intended to be in front of the foramen Monro [9]. In our revision case, the proximal end of the shunt was placed in the contralateral ventricle, which was dilated, with the help of transfontanelle ultrasound.

Therefore, utilization of transfontanellar ultrasound for proximal catheter placement in cases with an open fontanelle requiring external ventricular drainage, VP shunt placement, and revision aids in reducing proximal catheter failure.

\section{Conclusion}

Optimal catheter placement can reduce proximal catheter failure. In cases with an open fontanelle that require external ventricular drainage, VP shunt placement, or revision, proximal catheter failure can be reduced with transfontanellar ultrasound guidance.

\section{Additional file}

Additional file 1: Perioperative video recording for proximal catheter.

\section{Abbreviations}

CSF: Cerebrospinal fluid; CT: Computed tomography; VP: Ventriculoperitoneal

\section{Acknowledgements}

We would like to thank Dr. Houla Faris Al Asadi for the illustration. We also would like to acknowledge the http://www.makaletercume.com/ for their outstanding scientific proofreading and editing services that were provided for this manuscript.

\section{Funding}

There was no funding or any financial support for the current study.

\section{Availability of data and materials}

The dataset supporting the conclusion of this article is included within the article.

\section{Authors' contributions}

MS had a substantial role in the study design, data acquisition, and interpretation. In addition, ZNV and OAN actively participated in the data acquisition, interpretation, and revision of the manuscript and were involved critically in the study design and drafting of the manuscript. All authors read and approved the final manuscript.
Ethics approval and consent to participate

Since this study is a technical note, ethical approval was not required for this type of study our institute. However, the family was informed about the procedure and provided consent before the operation.

\section{Consent for publication}

Not applicable (the study does not involve identifiable human data)

\section{Competing interests}

The authors declare that they have no competing interests.

\section{Publisher's Note}

Springer Nature remains neutral with regard to jurisdictional claims in published maps and institutional affiliations.

\section{Author details}

${ }^{1}$ Department of Neurosurgery, Atakent Hospital, Adnan Menderes Mh. Ufuk Sok. No:7, 77200 Yalova, Turkey. ${ }^{2}$ Department of Radiology, Medicabil Hospital, Bursa, Turkey. ${ }^{3}$ Department of Neurosurgery, Ankara Numune Training and Education Hospital, Ankara, Turkey. ${ }^{4}$ Department of

Neurosurgery, Sanko University Konukoglu Hospital, Gaziantep, Turkey.

Received: 30 August 2018 Accepted: 9 January 2019

Published online: 28 January 2019

\section{References}

1. Wilson TJ, McCoy KE, Al-Holou WN, Molina SL, Smyth MD, Sullivan SE. Comparison of the accuracy and proximal shunt failure rate of freehand placement versus intraoperative guidance in parietooccipital ventricular catheter placement. Neurosurg Focus. 2016;41:E10.

2. Villavicencio AT, Leveque JC, McGirt MJ, Hopkins JS, Fuchs HE, George TM. Comparison of revision rates following endoscopically versus nonendoscopically placed ventricular shunt catheters. Surg Neurol. 2003;59:375-9 discussion 9-80.

3. Wilson TJ, Stetler WR Jr, Al-Holou WN, Sullivan SE. Comparison of the accuracy of ventricular catheter placement using freehand placement, ultrasonic guidance, and stereotactic neuronavigation. J Neurosurg. 2013;119:66-70.

4. Stein SC, Guo W. Have we made progress in preventing shunt failure? A critical analysis. J Neurosurg Pediatr. 2008;1:40-7.

5. Thomale UW, Schaumann A, Stockhammer F, et al. GAVCA study: randomized, multicenter trial to evaluate the quality of ventricular catheter placement with a mobile health assisted guidance technique. Neurosurgery. 2018;83(2):252-62.

6. Kestle JR, Drake JM, Cochrane DD, et al. Lack of benefit of endoscopic ventriculoperitoneal shunt insertion: a multicenter randomized trial. J Neurosurg. 2003;98:284-90.

7. Manfield JH, Yu KKH. Real-time ultrasound-guided external ventricular drain placement: technical note. Neurosurg Focus. 2017;43:E5.

8. Beez T, Sarikaya-Seiwert S, Steiger HJ, Hanggi D. Real-time ultrasound guidance for ventricular catheter placement in pediatric cerebrospinal fluid shunts. Childs Nerv Syst. 2015;31:235

9. Shkolnik A, McLone DG. Intraoperative real-time ultrasonic guidance of ventricular shunt placement in infants. Radiology. 1981;141:515-7 235-41.

\section{Submit your manuscript to a SpringerOpen ${ }^{\odot}$ journal and benefit from:}

- Convenient online submission

- Rigorous peer review

- Open access: articles freely available online

High visibility within the field

- Retaining the copyright to your article

Submit your next manuscript at $>$ springeropen.com 